\title{
Comparison of methodologies for TMY generation using15 years data for Chillan, Chile.
}

\author{
Carolina Sepúlveda ${ }^{1}$, Gabriel Merino ${ }^{2}$, Francisco Javier Pino ${ }^{3}$ \\ \& Juan Antonio Cañumir ${ }^{4}$. \\ ${ }^{1,2}$ (Departamento de Mecanización \& Energía, Facultad de Ingeniería Agrícola, Universidad de Concepción.) \\ 3 (Departamento de Ingeniería Energética, Escuela Superior de Ingenieros, Universidad de Sevilla) \\ ${ }^{4}$ (Departamento de Mecanización \& Energía, Facultad de Ingeniería Agrícola, Universidad de Concepción.)
}

\begin{abstract}
Typical meteorological year (TMY) is often used in the solar thermal field. Several methods to generate TMYs have been developed. However, results vary depending on the method used, which has a direct effect on the design of solar thermal systems. Because of this, it is necessary to establish a methodology for determining the TMY to be used. In this study were compared, five methods to generate TMYs with different weighting factors. TMYs were generated with weather data of a 15 -year period (1998-2012) for Chillán, Chile (latitude $36.6^{\circ}$ south). A solar thermal hot water system was evaluated in TRNSYS, using all TMYs generated. It was calculated Solar factor (SF), namely the fraction of solar energy used by the system throughout the year, for each TMYs and the years of data. Mean and median were then calculated for each month to all years. These values were compared to values obtained of SF from the TMYs. The TMY that presented the lowest difference in the 12 months with respect to those values was determined as the most representative. The selected TMY was generated by using ASRHAE based on dew point temperatures, and it is recommended for future studies for Chillán.
\end{abstract}

Keywords: - MATLAB, Meteorological variables, Thermal engineering, TRNSYS, Typical meteorological year.

\section{INTRODUCTION}

Energy is one of the precious resources in the world, the energy conservation becomes a hot topic around people, not just for deferring the depletion date of fossil fuel but also concerning the environmental impact due to energy consumption. Buildings, particularly fully air conditioned buildings, as one of the major energy consumption sectors, have great potential for energy conservation through energy efficient design, operation and maintenance. In designing new buildings, there are two major types of energy codes, namely prescriptive criteria and performance based criteria [1]. Energy is essential to economic and social development in the world and all energy simulation computer programs require weather data input to drive the thermal models within the simulation tools. A typical year approach can reduce the computational efforts in simulation and weather data handling by using one year instead of multiple years. Also, a consistent form of weather data is ensured so that results from different studies can be compared. Provided that the long term climatic data exist and are of sufficient quality, typical year weather data can be established from the multi-year dataset [2].

Many methods have been suggested to provide the typical meteorological year. Typical meteorological year has been presented in different types for examples TMY2 (NREL 1995) and WYEC2 (ASHRAE 1997) in the United States and Canada and TRY (CEC 1985) in the Europe. The TMY2 and WYEC2 typical weather years contain more solar radiation and illumination data than older formats such as TMY (NCDC 1983), WYEC (ASHRAE 1985) and TRY (NCDC 1981) [3].

The object of this job was development a TMY for Chillan city for future design or studies in thermal engineering, this is the first TMY development in Chile, given that in Chile no account with the necessary years of meteorological data required for its construction. Finally the results of all TMYs were compared through a simulation in TRNSYS, to decide which method could be recommended as the best in the Chillan area. $[4,5]$. 


\begin{tabular}{|c|c|c|c|}
\hline \multicolumn{4}{|c|}{ Nomenclature } \\
\hline ASHRA & American Society of Heating, & TMY & typical meteorological year \\
\hline $\mathrm{E}$ & Refrigerating, & & \\
\hline & and Air-Conditioning Engineers & WS & weighted sum \\
\hline $\mathrm{CDF}$ & cumulative distribution functions & $\mathrm{e}$ & steam of pressure, in present moment \\
\hline DT & Dew point temperature & $\mathrm{e}_{\mathrm{S}}$ & saturation of pressure of steam $[\mathrm{Pa}]$ \\
\hline FS & Finkelstein- Schafer & $\mathrm{m}$ & Day number of year \\
\hline $\mathrm{FS}_{\mathrm{i}}$ & FS statistic for index & $\mathrm{n}$ & the number of daily readings in a month \\
\hline NREL & National Renewable Energy Laboratory & $\mathbf{t}$ & ambient temperature or of dry bulb $\left[{ }^{\circ} \mathrm{C}\right]$ \\
\hline NSRDB & National Solar Radiation Data Base (W) & $t_{d}$ & dew point temperature $\left[{ }^{\circ} \mathrm{C}\right]$ \\
\hline $\mathrm{G}_{\mathrm{SC}}$ & $\begin{array}{l}\text { radiation outside the terrestrial } \\
\text { atmosphere }\end{array}$ & $\mathrm{w}_{\mathrm{i}}$ & weighting for index \\
\hline $\mathrm{H}_{\mathrm{d}}$ & diffuse radiation monthly & & \\
\hline $\mathrm{K}_{\mathrm{T}}$ & daily clearness index & & \\
\hline $\mathrm{Q}_{\mathrm{AUX}}$ & back up heat & Greek & Symbols \\
\hline Qos & heat useful obtain of sol & $\delta_{\mathrm{i}}$ & absolute difference between the long-term \\
\hline $\mathrm{Q}_{\mathrm{T}}$ & all heat of system in TRNSYS & & $\mathrm{CDF}$ and the candidate month $\mathrm{CDF}$ at $\mathrm{xi}$ \\
\hline RH & relative humidity & $\delta$ & solar declination angle \\
\hline $\mathrm{SD}$ & sum different & $\phi$ & Latitude angle \\
\hline SF & solar factor & $\omega_{\mathrm{S}}$ & angular hours \\
\hline
\end{tabular}

\section{METHODS USED TO DEVELOP THE TMYS}

The five methods used to develop the TMYs were developed based on the ones described by Sandia laboratories. Data of a 15-year period were provided by the Faculty of Agricultural Engineering of the University of Concepción, Chillán. The method selects a year between 1998 and 2012, which best represents the behavior of the weather data evaluated. The calculation is done using daily data, as observed in Table 1 . Difference between methods is the weighting index (w) of each weather datum (see Table 1). The Sandia method considers 4 steps:

Step 1 - By using cumulative distribution functions (CDFs) is calculated for each month of january to december, for the fifteen years and the CDFs calculation is repeated but this time with the data of 15 years for each month. Monthly CDFs are compared to the long-term (15 years) CDF by using the Finkelstein-Schafer (FS) statistics method. This is conducted for each meteorological variable.

$$
F S=(1 / n) \cdot \sum_{i=1}^{n} \delta_{i}
$$

As meteorological indices present different weighting indices depending on the method used, a weighted sum (WS) is calculated per month for every year by using the following equation:

$$
W S=\sum w_{i} \cdot F S_{i}
$$

Step 2 - Must choose 5 years (candidates) for month between the 15 years. The five candidate are selected by calculating the mean and median between yearly cumulative distribution and the cumulative distribution of all of the years for all variables.

Step 3 - One of the five years is selected by eliminating the years that present many consecutive days with dry bulb temperatures above the 67th percentile (consecutive warm days) or below the 33rd percentile (consecutive cool days), or with global horizontal radiation below the 33rd percentile (consecutive low radiation days). These criteria include years that present more consecutive days above or below these percentiles (runs), as well as the years that present zero runs.

The year that best meets these persistence criteria is selected as the year to generate the TMY.

Step 4 - The 12 selected months are now concatenated to make a complete year. Discontinuities at the month interfaces are smoothed for 6 hours each side (at the end of the month and start of the next month) using curve fitting techniques. For example, 12 hours corresponding to the data of the selected years for January and February are averaged [7-9]. 
Comparison of methodologies for TMY generation using 15 years data for Chillan, Chile.

Table 1. Meteorological indices and weighting factors for the FS statistics.

\begin{tabular}{lllllll}
\hline Parameters & index & Sandia & NREL & ASHRAE & Lui Yang & Yingni Jiang \\
\hline Dry bulb temperature & Max & $1 / 24$ & $1 / 20$ & $5 / 100$ & $1 / 24$ & $1 / 20$ \\
& Min & $1 / 24$ & $1 / 20$ & $5 / 100$ & $1 / 24$ & $1 / 20$ \\
& Mean & $2 / 24$ & $2 / 20$ & $30 / 100$ & $2 / 24$ & $3 / 20$ \\
Dew point temperature & Max & $1 / 24$ & $1 / 20$ & $2.5 / 100$ & - & $1 / 32$ \\
or Relative Humidity & Min & $1 / 24$ & $1 / 20$ & $2.5 / 100$ & - & $1 / 20$ \\
& Mean & $2 / 24$ & $2 / 20$ & $5 / 100$ & $4 / 24$ & $2 / 20$ \\
Wind & Max & $2 / 24$ & $1 / 20$ & $5 / 100$ & $2 / 24$ & $1 / 20$ \\
& Mean & $2 / 24$ & $1 / 20$ & $5 / 100$ & $2 / 24$ & - \\
Solar radiation & Global & $12 / 24$ & $5 / 20$ & $40 / 100$ & $12 / 24$ & $5 / 20$ \\
& Direct & - & $5 / 20$ & - & - & $5 / 20$ \\
\hline
\end{tabular}

\section{WEATHER DATA PROCESSING}

The first step was to review files and verify measurements units in order to detect missing data in the files. If missing values were detected (not recorded due to problems with measuring equipment), these were completed using different mathematical methods depending on the number of missing values. Linear, quadratic or cubic approximations were used to obtain the most representative curve in R2, as well as the behavior of the weather variable throughout the day.

When more than 30 values were missing per day, a method consisting of calculating the average of the averages was used. Available values of the different years were averaged. It then recalculates the average eliminating one year of data, and this step is repeated for each of the years that data are available, to finally calculate the average of the all averages calculated. The obtained value was used to fill in the missing data. This method was implemented in Matlab software.

To create a TMY, a program was developed in Matlab software to obtain tables per year with daily data of meteorological parameters. Maximum, minimum and mean values required were identified and saved in Excel files. Dew point temperature (DT) was calculated based on ambient temperature (T) and relative humidity $(\mathrm{RH})$ using the following equations [18].

$$
\% R H=\left(e / e_{s}\right) \cdot 100
$$

Where, saturation pressure of water vapor (es) is expressed as:

$$
e_{s}=\exp \left(\operatorname{Ln}(611.2)+\left(\frac{17.62 \cdot t}{243.12+t}\right)\right)
$$

Once water vapor saturation pressure was calculated at ambient temperature, partial water vapor pressure (e) was calculated based on RH by applying the equation (3). At dew point, partial water vapor pressure in air equals the water vapor saturation pressure.

$$
e=e_{S} \cdot D T
$$

Therefore, dew point temperature (DT) is:

$$
D T=\frac{243.12-\operatorname{Ln}(e)-1559.72}{24.035-\operatorname{Ln}(e)}
$$

Direct solar radiation [MJ/m2] per day was calculated based on numerical integration in Matlab using Simpson's rule at 15 minute intervals, while direct solar radiation was calculated based on equations adapted by Klein \& Duffie (1978). This required calculating sun declination angle, hour angle, daily extraterrestrial radiation on a horizontal surface, and daily clarity index, as follows [19]:

Sun declination $(\delta)$ was calculated by two different methods (equations 7 and 8) and resulting values were averaged.

$$
\begin{aligned}
& \delta=23.45 \cdot \sin (360 \cdot(284+m / 365)) \\
& \delta=\frac{180}{\pi} \cdot(0.006918-0.39912 \cdot \cos B+0.070257 \cdot \sin B-0.006758 \cdot \cos 2 B+0.000907 . \\
& \sin 2 B-0.002697 \cdot \cos 3 B+0.00148 \cdot \sin 3 B)
\end{aligned}
$$

Where,

$$
B=2 \cdot \pi \cdot(m-1) / 365
$$

Extraterrestrial radiation on a horizontal surface (Ho) was calculated using the equation: 


$$
H_{O}=\frac{24 \cdot 3600 \cdot G_{S C}}{\pi} \cdot\left[\left(1+0.033 \cdot \cos \left(\frac{360 \cdot m}{365}\right)\right) \cdot\left(\cos \phi \cdot \cos \delta \cdot \operatorname{sen} \omega_{S}+\frac{\pi \cdot \omega_{S}}{180} \cdot \sin \phi \cdot \sin \delta\right)\right]
$$

Where solar angle $(\omega \mathrm{S})$ at sunset was calculated as:

$\omega_{S}=(180 / \pi) \cdot \operatorname{acos} \cdot(-\tan \phi \cdot \tan \delta)$

Clarity index (KT) was calculated as:

$$
K_{T}=H / H_{O}
$$

The beam and diffuse radiation $(\mathrm{Hb} \& \mathrm{Hd})$,

For $\omega \mathrm{S} \leq 81.4^{\circ}$ and $\mathrm{KT}<0.715$

$$
\frac{H_{d}}{H}=1.0-0.2727 \cdot K_{T}+2.4495 \cdot K_{T}^{2}-11.9514 \cdot K_{T}^{3}+9.3879 \cdot K_{T}^{4}
$$

For $\omega \mathrm{S} \leq 81.4^{\circ}$ and $\mathrm{KT} \geq 0.715$

$$
\frac{H_{\text {d }}}{H}=0.143
$$

For $\omega \mathrm{S}>81.4^{\circ}$ and $\mathrm{KT}<0.722$

$$
\frac{H_{d}}{H}=1.0+0.2832 \cdot K_{T}-2.5557 \cdot K_{T}^{2}+0.8448 \cdot K_{T}{ }^{3}
$$

For $\omega \mathrm{S}>81.4^{\circ}$ and $\mathrm{KT} \geq 0.722$

$$
\frac{H_{d}}{H}=0.175
$$

Finally, monthly beam radiation was calculated as:

$$
\mathrm{Hb}=\mathrm{H}-\mathrm{Hd}
$$

Once data were obtained, TMY files were created through a program developed in Matlab using the different methods described in Table 1. Dew point temperature or relative humidity values were used, which generated a total of 10 different TMYs.

\section{IV.}

EVALUATION OF THE TMYS

The 10 TMYs generated from weather data of a 15 year-period for Chillán were evaluated using a hot water system simulated in TRNSYS (Figure 1). Parameters for solar-plate collectors used in the simulation were the following: efficiency coefficients; $\mathrm{a} 0=0.747[\mathrm{]} ; \mathrm{a} 1=15.0984[\mathrm{~kJ} / \mathrm{h} \mathrm{m} 2 \mathrm{~K}]$, y a2 $=0.0324[\mathrm{~kJ} / \mathrm{h} \mathrm{m} 2 \mathrm{~K} 2]$ and the panel inclination angle was $45^{\circ}$. Figure 2 shows daily water use, which is used to calculate hot water flow (FW). This calculation was performed considering water use of $30 \mathrm{~L}$ of water per person in a 22-apartment building and 4 people per apartment, as shown in Equation 18.

Monthly and annual solar factor (SF) values were evaluated for the 10 TMYs and the 15 years of data for Chillán (25 years in total) under different system operating conditions, based on useful heat obtained from the sun (QOS), total heat of system given by TRNSYS (QT) and back up heat (QAUX), as observed in Table 2.

$$
\begin{aligned}
& F_{W}=30 \cdot 4 \cdot(22 / 24) \cdot \text { Daily profile }[1 / \mathrm{h}] \\
& S F=Q_{O S} / Q_{T} \\
& Q_{T}=Q_{O S}+Q_{A U X}
\end{aligned}
$$

Table 2. Variable modification in the different simulations generated in TRNSYS

\begin{tabular}{cccc}
\hline $\begin{array}{c}\text { System } \\
\text { configuration }\end{array}$ & $\begin{array}{c}\text { Collector area } \\
{\left[\mathrm{m}^{2}\right]}\end{array}$ & $\begin{array}{c}\text { Temperature hot water } \\
{\left[{ }^{\circ} \mathrm{C}\right]}\end{array}$ & Volume of hot water stored $\left[\mathrm{m}^{3}\right]$ \\
\hline A & 40 & 45 & 3.00 \\
B & 40 & 60 & 3.00 \\
C & 40 & 75 & 3.00 \\
D & 50 & 60 & 3.00 \\
E & 60 & 60 & 3.00 \\
F & 50 & 60 & 3.75 \\
G & 50 & 60 & 4.00 \\
\hline
\end{tabular}




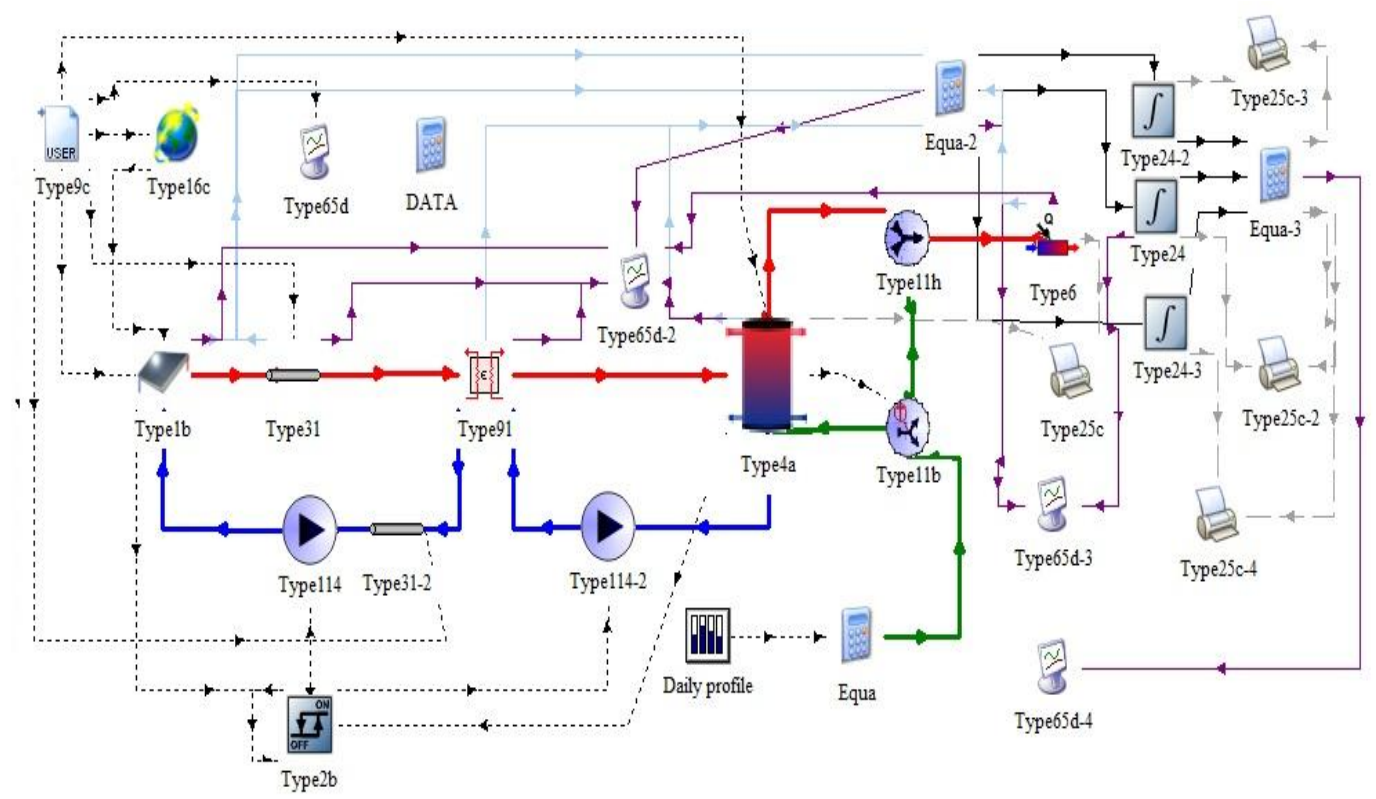

Fig. 1. Diagram of thermal sanitary system for hot water simulated in TRNSYS [19]

SF factor was used as an evaluation method to determine which of the 10 TMYs best represented the 15 years of weather data for Chillan. Monthly SF values of the 10 TMYs were compared with the SF values calculated from the weather data measured by UdeC during a period of 15 years for Chillan. The choise of the TMY was conducted based on the value closest to the mean of the monthly average SF value calculated from the 15 years of weather data (1998-2012). Then, the TMY with the lowest sum value of the 12 months based on the differences between the mean and the average was selected as the most representative TMY for Chillán. This was done in all cases presented in Table 2 to determine if the selected TMY changed when varying operating conditions, and to ensure that the selected TMY was the most representative for Chillan.

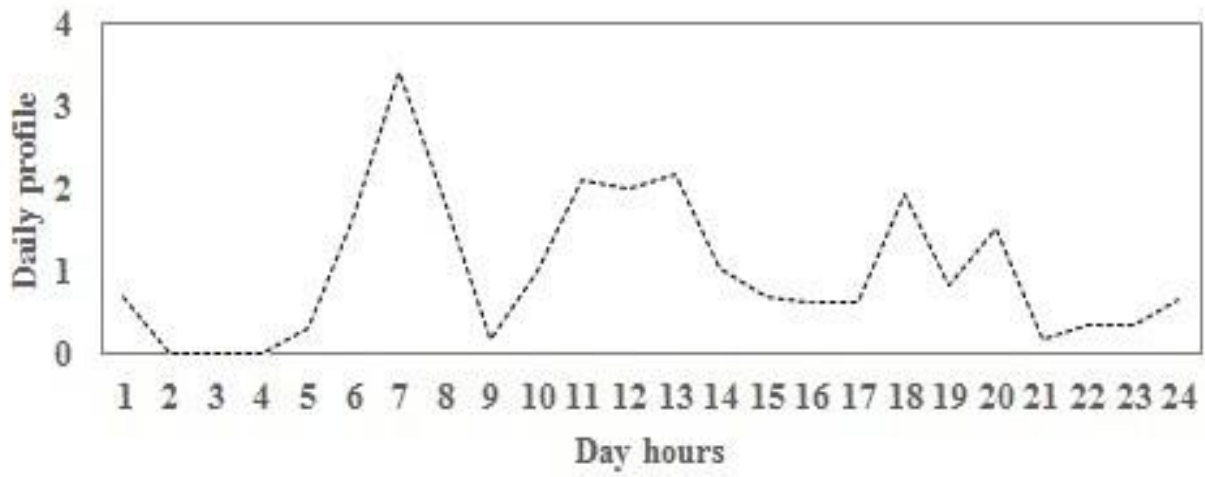

Fig 2. Daily profile of the sanitary thermal system for hot water simulated in TRNSYS

\section{RESULTS AND DISCUSSION}

Table 3 shows the 10 TMYs obtained using different calculation methods with their respective weighting factors. This table shows that there are differences between the results with different methodologies used to calculate TMY. Also observed differences if used the dew point temperature (TD) or relative humidity (RH) is used as the calculation parameter. The year 1998 was repeated in the more opportunities in the different TMYs. The same TMY data set was obtained using NREL and Yingni Jiang simulation methods when calculated based on DT. This is because the weighting factors of both methods are very similar. However, when calculated based on RH, the year selected for March and April is different. In all TMYs the years 1998, 1998 and 2001 were selected for the months of February, July and August, respectively. 
Comparison of methodologies for TMY generation using 15 years data for Chillan, Chile.

Table 3. Results of the TMYs selection for five different methods using dew point temperature or relative humidity

\begin{tabular}{lllllllllll}
\hline \multirow{2}{*}{ MES } & \multicolumn{3}{c}{ Sandia (S) } & \multicolumn{2}{c}{ NREL (N) } & \multicolumn{2}{c}{ ASHRAE (A) } & \multicolumn{2}{c}{ Lui Yang (L) } & \multicolumn{2}{c}{ Yingni Jiang (Y) } \\
& DT & RH & DT & RH & DT & RH & DT & RH & DT & RH \\
\hline E & 2003 & 2011 & 2011 & 2011 & 1999 & 2011 & 2011 & 2011 & 2011 & 2011 \\
F & 1998 & 1998 & 1998 & 1998 & 1998 & 1998 & 1998 & 1998 & 1998 & 1998 \\
M & 1998 & 1998 & 1998 & 1998 & 2003 & 2003 & 1998 & 1998 & 1998 & 1999 \\
A & 1998 & 1999 & 1999 & 1998 & 1998 & 1999 & 1998 & 2002 & 1999 & 1999 \\
M & 1998 & 1998 & 1998 & 1998 & 1999 & 1998 & 1998 & 1998 & 1998 & 1998 \\
J & 1998 & 1998 & 2004 & 1998 & 2010 & 1998 & 1998 & 1998 & 2004 & 1998 \\
J & 1998 & 1998 & 1998 & 1998 & 1998 & 1998 & 1998 & 1998 & 1998 & 1998 \\
A & 2001 & 2001 & 2001 & 2001 & 2001 & 2001 & 2001 & 2001 & 2001 & 2001 \\
S & 2008 & 2008 & 2008 & 2011 & 2008 & 2008 & 2008 & 2011 & 2008 & 2011 \\
O & 1999 & 1998 & 1999 & 1998 & 1999 & 1998 & 1999 & 1998 & 1999 & 1998 \\
N & 2007 & 1998 & 2007 & 1998 & 2007 & 1998 & 1999 & 1998 & 2007 & 1998 \\
D & 2004 & 1998 & 2004 & 1998 & 2004 & 1998 & 2009 & 1998 & 2004 & 1998 \\
\hline
\end{tabular}

Table 4 shows the results for solar factor (SF) determined from different simulations. SF values range from 0.48 to 0.85 when TMY was generated with TR, while values range from 0.45 to 0.85 when calculated with RH. Regarding SF, hot water temperature required in the configurations solar systems A and C presented the highest and lowest values, respectively. This means that water temperature is highly relevant in the design of these systems. The highest difference was recorded when using the Sandia method calculated with DT, and the lowest when using ASHRAE method calculated with RH. In order to better see the SF variation when modifying hot water temperature, collector area or storage tank volume, were performed three graphs with SF values (Figures 3,4 and 5).

Figure 3 shows a big variation of $\mathrm{SF}$ values with temperature, which increases as hot water temperature decreases from 45 to $75^{\circ} \mathrm{C}$. As the same system has a lower power consumption, solar energy is used more efficiently. For a TMY obtained from DT, equation for this behavior is $\mathrm{SF}=0.1679 \cdot \mathrm{T}+0.9882$, with $\mathrm{R}^{2}=1$. Results also indicate that the larger the collector area, the higher the SF obtained (Figure 4). This occurs because there is a larger amount of solar energy.

Figure 5 shows that variation in tank volume per TMY is moderately significant, when compared to the other two variables discussed before. However, a variation is observed if the method is calculated with DT or RH. Therefore, the use one or the other meteorological variable results in different TMY data sets. Finally, it can be concluded that simulation results with TRNSYS show what actually happens in this type of hot water systems.

Table 4. Result annual solar factor (SF) for different TMYs, developed with dew temperature (DT) or relative humidity (RH)

\begin{tabular}{ccccccccccc}
\hline $\begin{array}{c}\text { System } \\
\text { configuration }\end{array}$ & S-DT & S-RH & N-DT & N-RH & A-DT & A-RH & L-DT & L-RH & Y-DT & Y-RH \\
\hline A & 0.858 & 0.858 & 0.841 & 0.848 & 0.820 & 0.856 & 0.859 & 0.844 & 0.841 & 0.801 \\
B & 0.581 & 0.635 & 0.588 & 0.622 & 0.570 & 0.634 & 0.595 & 0.612 & 0.588 & 0.619 \\
C & 0.493 & 0.539 & 0.499 & 0.528 & 0.484 & 0.538 & 0.506 & 0.520 & 0.499 & 0.453 \\
D & 0.636 & 0.717 & 0.672 & 0.702 & 0.653 & 0.715 & 0.681 & 0.692 & 0.679 & 0.699 \\
E & 0.703 & 0.767 & 0.730 & 0.751 & 0.711 & 0.764 & 0.742 & 0.742 & 0.730 & 0.745 \\
F & 0.636 & 0.717 & 0.672 & 0.702 & 0.653 & 0.715 & 0.681 & 0.692 & 0.679 & 0.699 \\
G & 0.633 & 0.715 & 0.669 & 0.700 & 0.650 & 0.713 & 0.679 & 0.690 & 0.669 & 0.698 \\
\hline
\end{tabular}




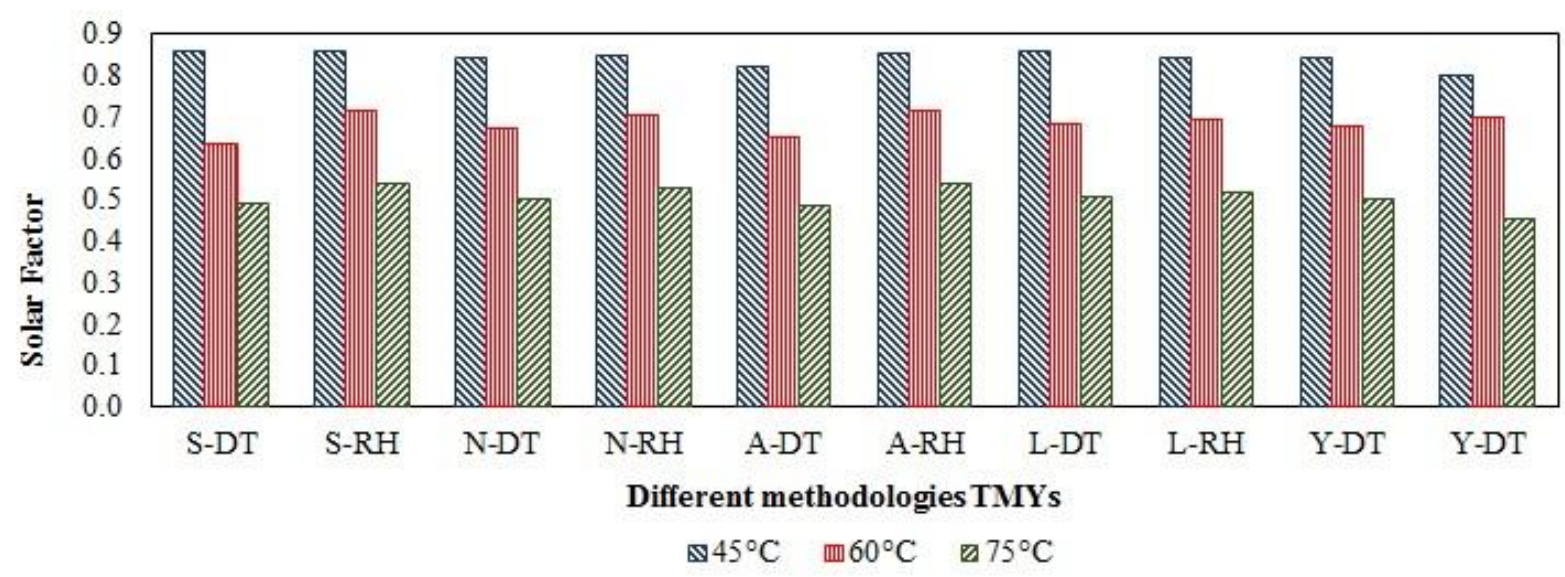

Fig. 3. Different annual solar factors obtained for TMYs calculated using different methods, by varying the temperature of hot water required.

To select the TMY for Chillan, differences in average and mean monthly of SF values were analyzed by comparing SF values of 15 years of data and those obtained in each of the evaluated TMYs (Table 5). Values in parentheses indicate the position of the selected TMY with respect to the 25 years of data evaluated. Table 5 includes the most and least representative TMY for designing solar thermal systems for Chillán. The TMY chosen for all evaluated cases was calculated by ASHRAE based on DT (A-DT). Finally the table gives the sum of the differences (SD) of every month from January to December. Values were obtained using the 10 different TMYs evaluated, and compared to the average and mean of SF values of the 15 years of data for Chillan.

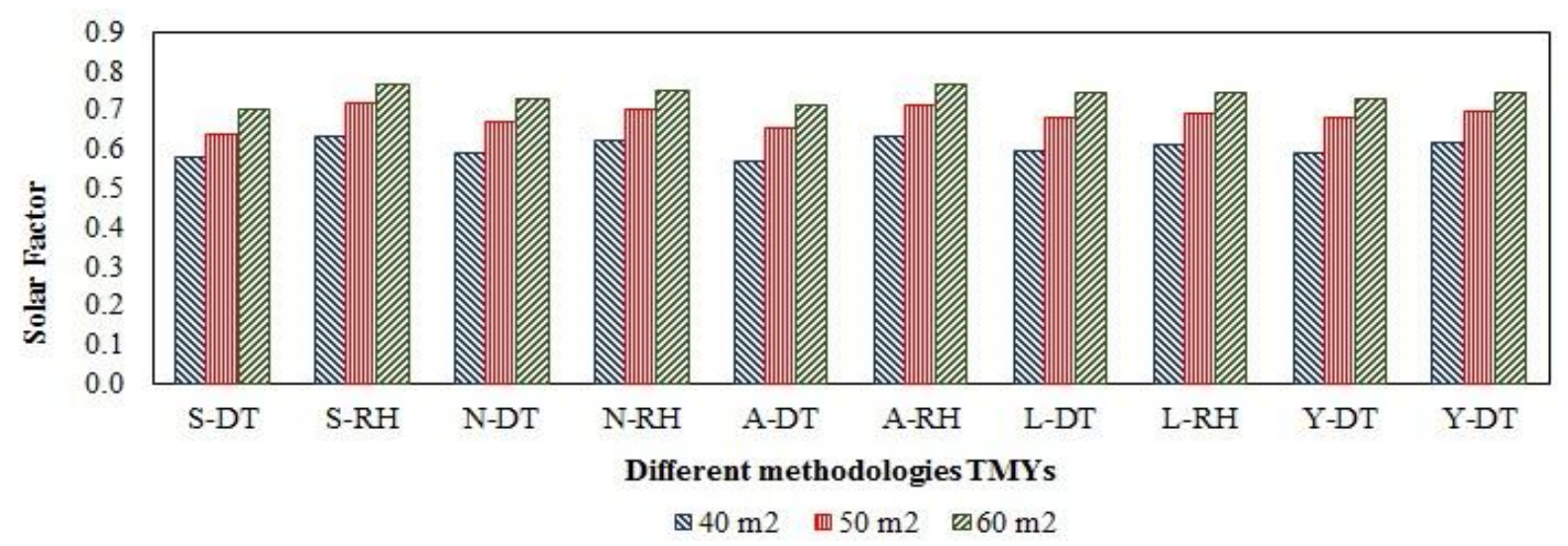

Fig. 4. Different annual solar factors obtained for TMYs calculated using different methods, by varying the collector area

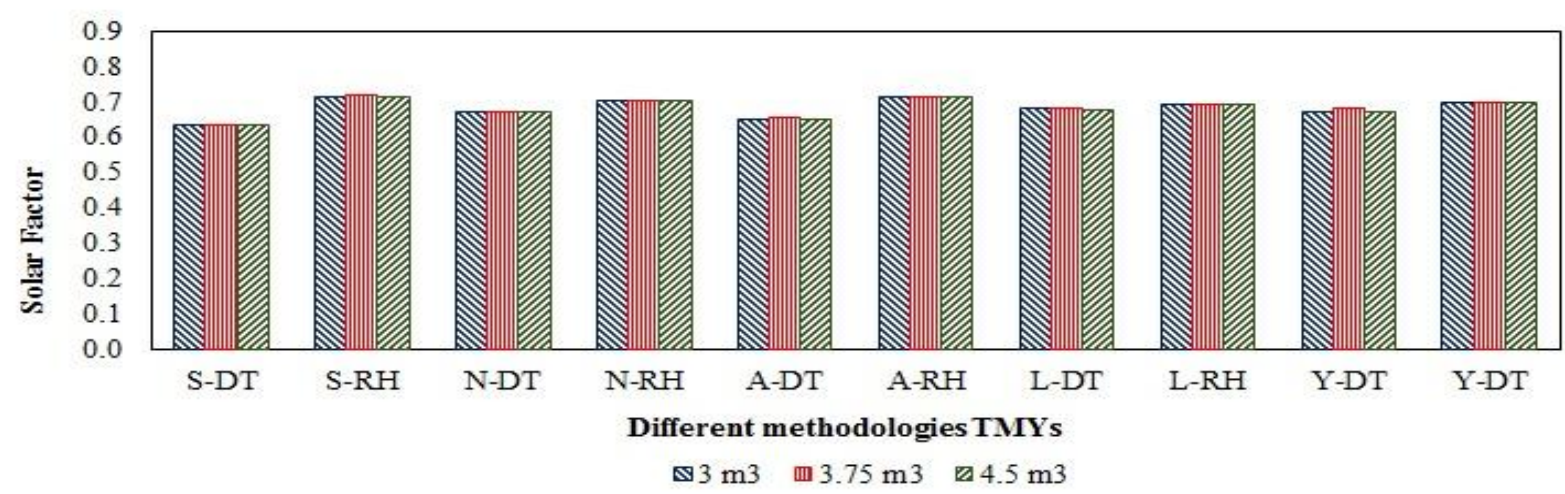

Fig 5. Different annual solar factors obtained for TMYs calculated using different methods, by varying the volume of the storage of hot water. 
Comparison of methodologies for TMY generation using 15 years data for Chillan, Chile.

Table 5. TMY selected and the monthly difference of the sum of the mean and median.

\begin{tabular}{lrrrrrl}
\hline $\begin{array}{c}\text { System } \\
\text { configuration }\end{array}$ & $\begin{array}{c}\text { Least } \\
\text { SD }\end{array}$ & TMYs selected & $\begin{array}{c}\text { Higher } \\
\text { SD }\end{array}$ & Least SD & TMYs select & Higher SD \\
\hline A & 2006 & ASRAHE DT (6/25) & 2007 & 0.9661 & 1.1551 & 3.9112 \\
B & 2010 & ASRAHE DT (4/25) & 2007 & 1.1629 & 1.3454 & 4.5672 \\
C & 2006 & ASRAHE DT (3/25) & 2007 & 0.8968 & 1.0092 & 3.4958 \\
D & 2010 & ASRAHE DT (4/25) & 2007 & 1.1629 & 1.3454 & 4.5672 \\
E & 2011 & ASRAHE DT (4/25) & 2007 & 1.0777 & 1.3879 & 4.190 \\
F & 2010 & ASRAHE DT (4/25) & 2007 & 1.1629 & 1.3454 & 4.5672 \\
G & 2010 & ASRAHE DT (4/25) & 2007 & 1.1614 & 1.3652 & 4,5779 \\
\hline
\end{tabular}

Figures 6, 7 and 8 contain graphs showing the results of SF for each one of the 15 years and for the selected TMY, what allows identifying how representative the selected TMY. Year 1998 shows the highest SF value but is the year that most repeated among the TMYs created. TMY data sets are developed from daily weather data, but the results of TMY data sets is in hourly weather data, which are used in the TRNSYS simulation software. The year 2003 presents the lowest SF value, and it is selected for the month of March by the two TMYs generated by ASHRAE method. It is observed that the selected TMY is between the results of 1998 and 2003, but it is slightly higher than the annual average of SF values obtained from the different years. The year that best represents the result of annual SF of all years is shown in Table 6, being 1999 and 2006 the years with the most repeated. When using simulation C, the year 2006 was also the one that best represents both annual and monthly SP values.

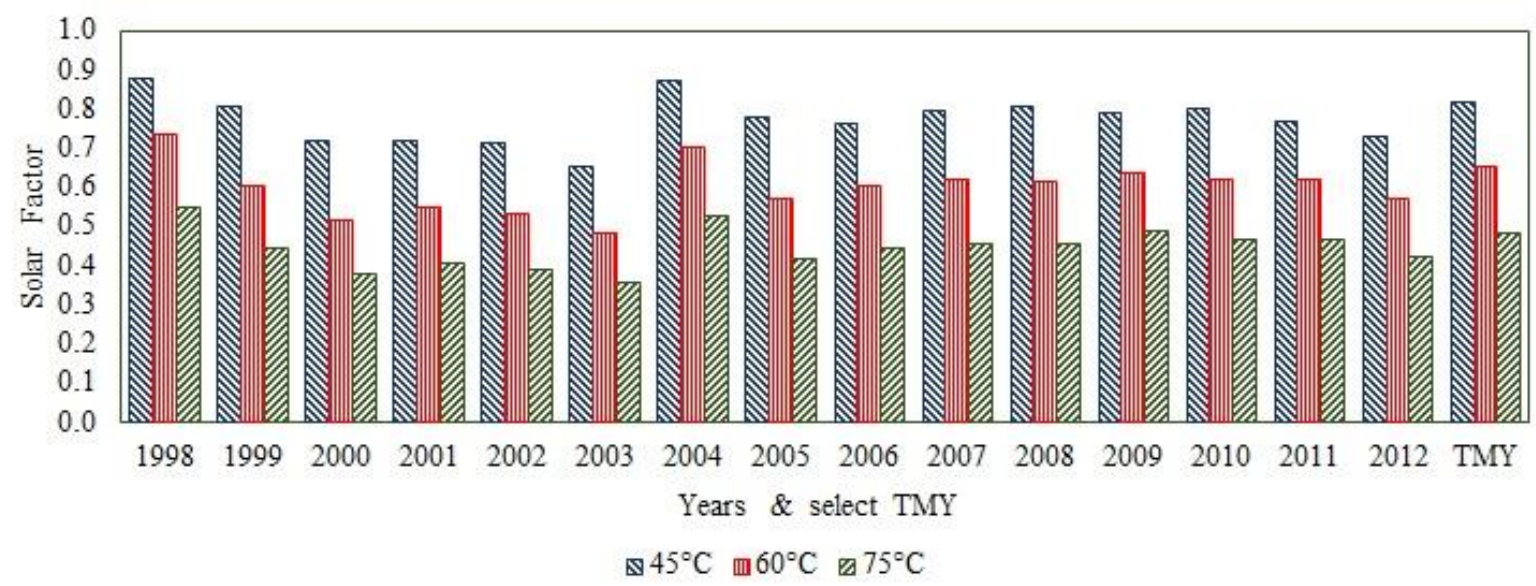

Fig 6. SF values obtained with the different years and TMY selected according at the different temperatures of hot water requirement.

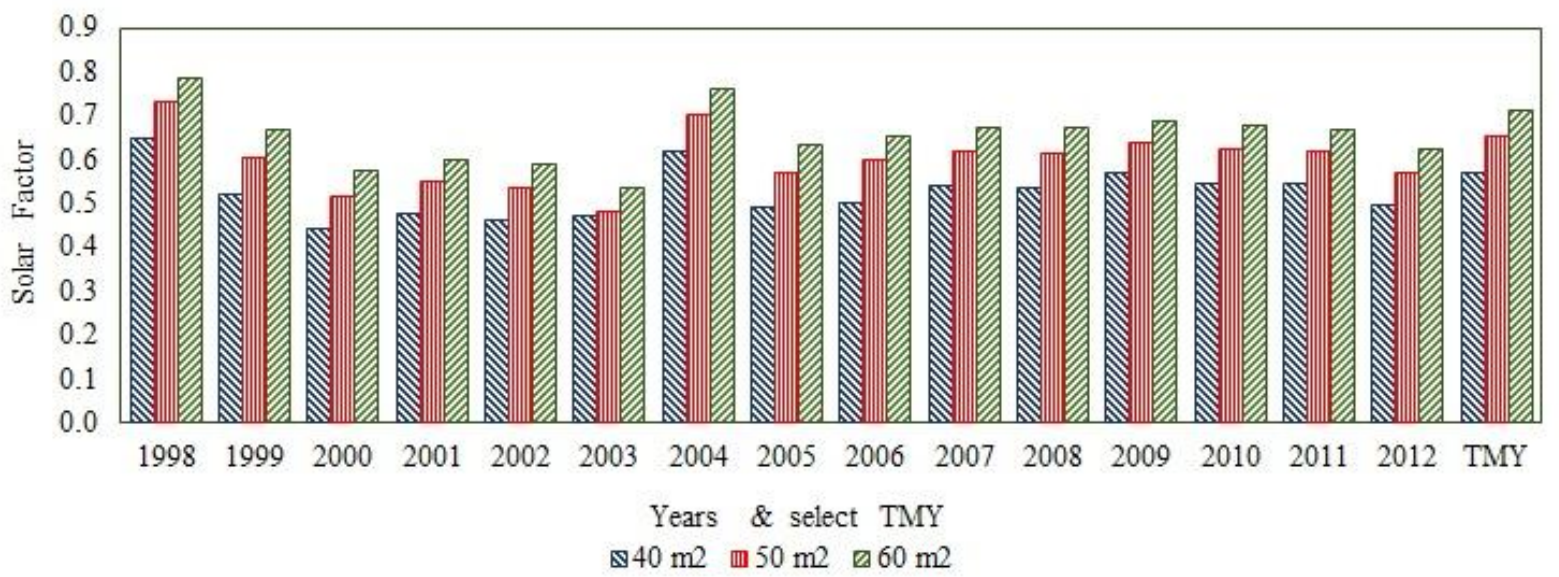

Fig 7. SF values obtained with the different years and TMY selected according at the different areas. 


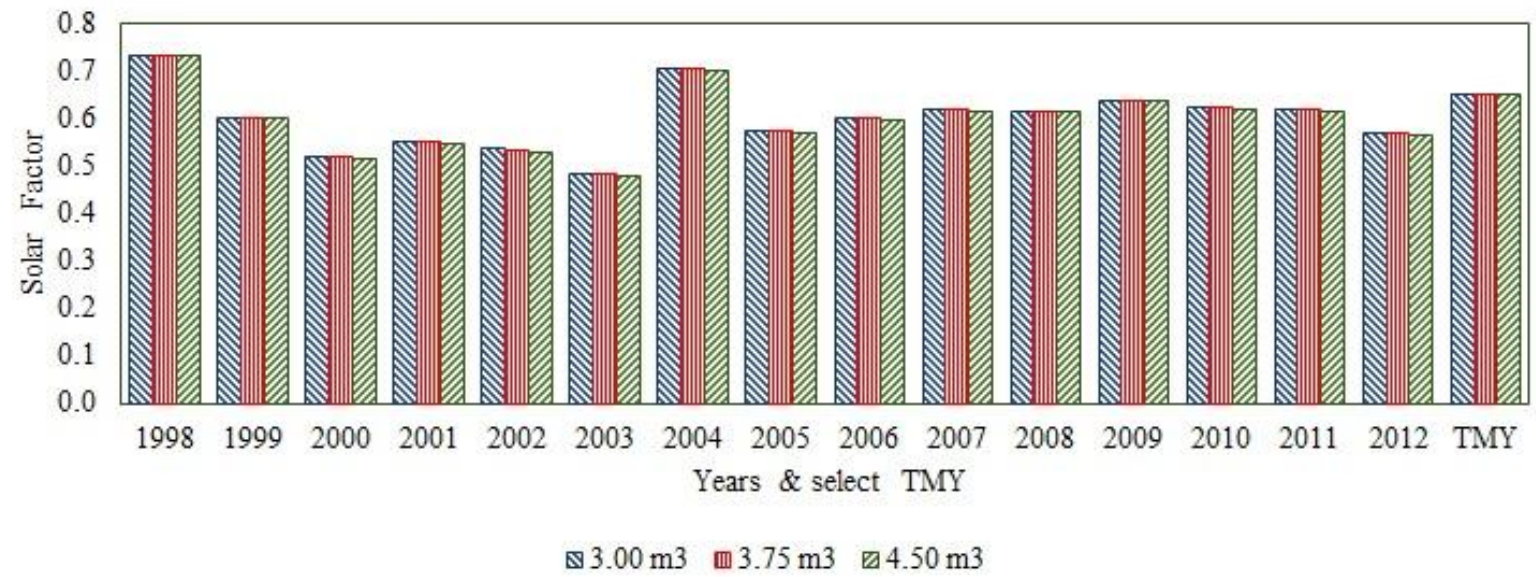

Fig 8. SF values obtained with the different years and TMY selected according at the different volumes of storage.

Table 6. Year with the less difference found between the mean and median of annual SF, calculated with 15 years of data.

\begin{tabular}{lccccccc}
\hline $\begin{array}{l}\text { System } \\
\text { configuration }\end{array}$ & $\mathrm{A}$ & $\mathrm{B}$ & $\mathrm{C}$ & $\mathrm{D}$ & $\mathrm{E}$ & $\mathrm{F}$ & $\mathrm{G}$ \\
\hline Years & 2005 & 1999 & 2006 & $1999-2006$ & $1999-2006$ & $1999-2006$ & $1999-2006$ \\
SF & 0.7780 & 0.5218 & 0.4456 & $0.6032-0.6023$ & $0.6672-0.6570$ & $0.6030-0.6021$ & $0.6003-0.5986$ \\
\hline
\end{tabular}

Figures 9, 10 and 11 show how the SF calculated from the selected TMY adjusts the SF monthly values calculated from the 15 years of data of (1998-2012). It can be observed that monthly values vary considerably, with a difference of up to 0.5 between the results of the year having the highest SP value and those of a the year with the lowest value in a given month. This may be due to the characteristics of the climate in Chile, years moving from dry or rainy weather conditions during El Niño or La Niña years. Solar radiation levels are lower in rainy years than in dry years, while summer months have higher SF levels than the winter months. The difference in monthly results for each year confirms the importance of a proper selection for each month that makes up a TMY.

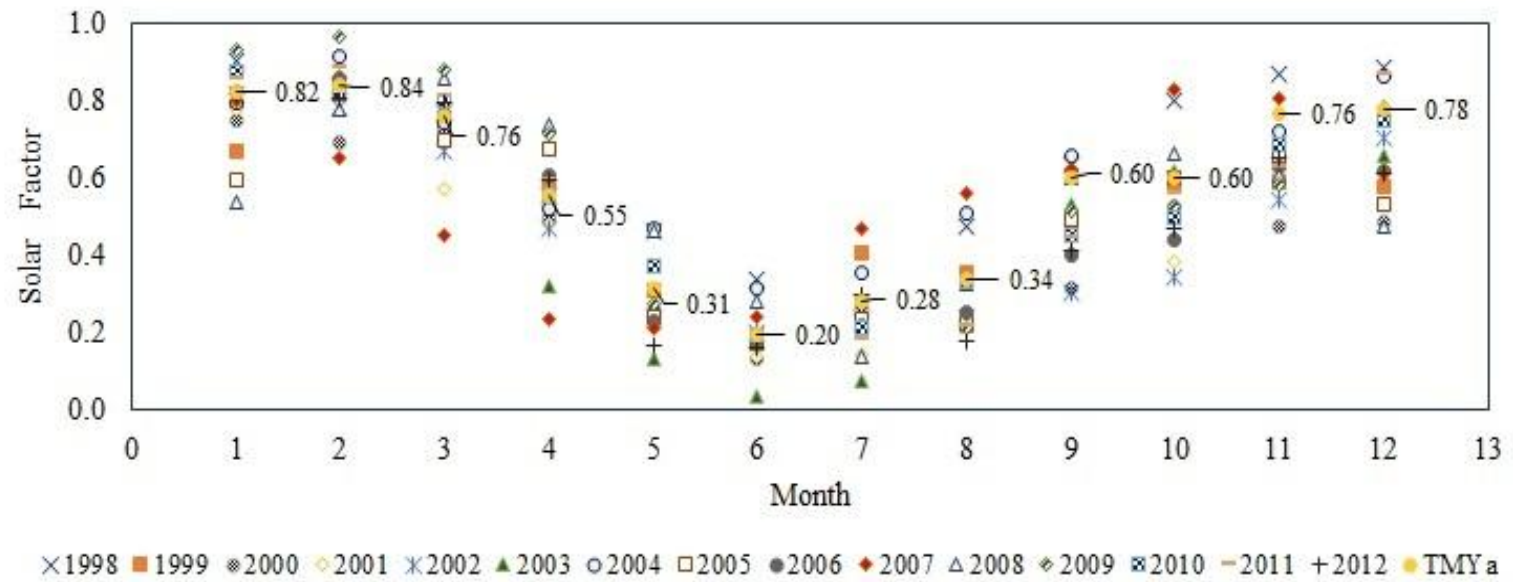

Fig 9. Results of monthly SF obtained with the different years and the selected TMY in the configuration B. 


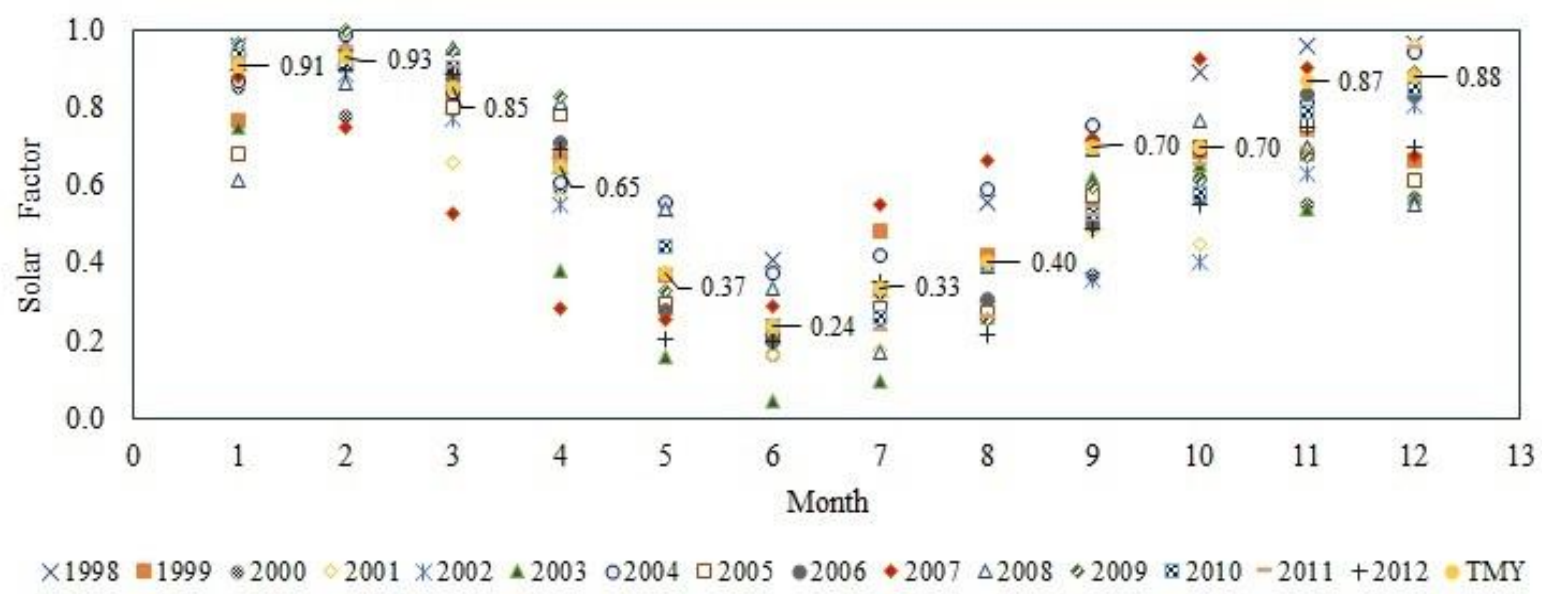

Fig 10. Results of monthly SF obtained with the different years and the selected TMY in the configuration D.

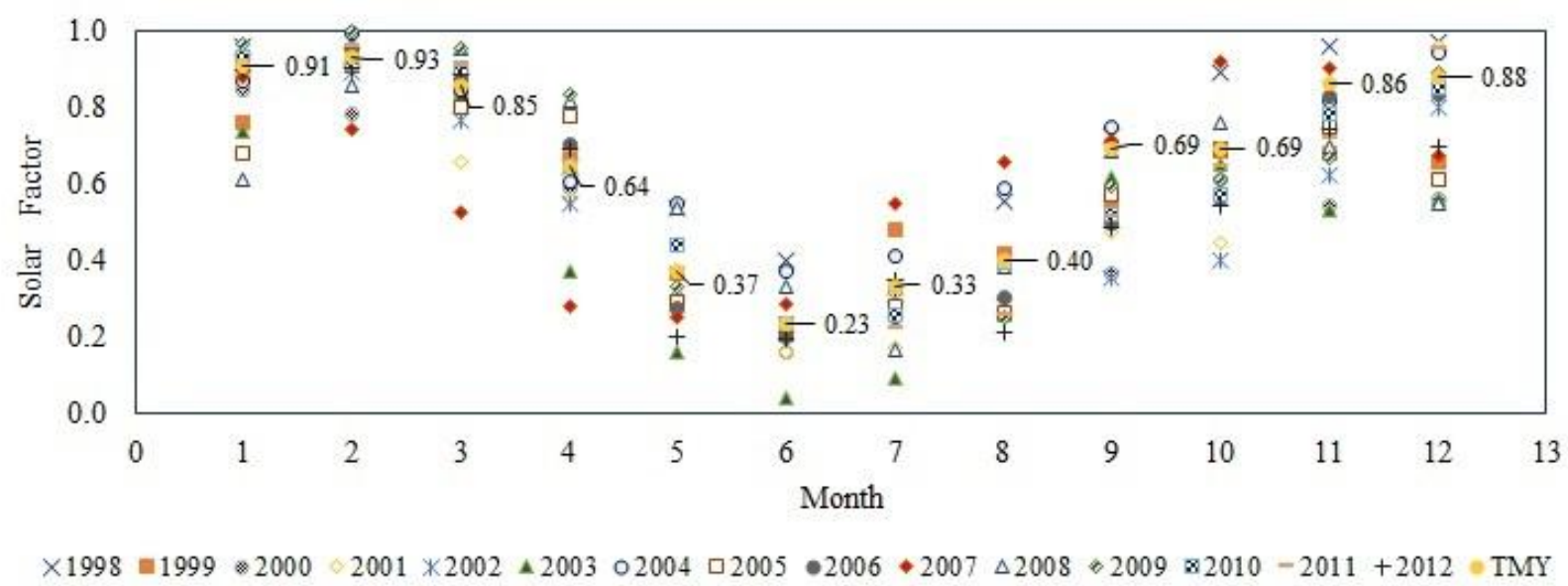

Fig 11. Results of monthly SF obtained with the different years and the selected TMY in the configuration G.

\section{CONCLUSIONS}

Based on the data analyzed for Chillan, it can be concluded that the use of dew point temperature or relative humidity to create TMY data sets, generates different TMYs for the same method. The analysis of the results allows recommending the use of dew point temperature to create TMY date sets, even if the development of TMYs is based on relative humidity and air temperature measurements.

Weighting factors of each individual method for TMYs development generates different typical meteorological years. February, June and August were the months in which all TMYs coincide and corresponded to the years 1998, 1998 and 2001, respectively. The same TMY was only obtained using NREL and Jiang Yingni methods based on DT measurements. Therefore, applying one of these methods, even with similar factors, implies obtaining different results in most of the cases. As this will undoubtedly affect the calculations in thermal system designs, it is necessary to identify which method best represents the place so that subsequent calculations can be carried out based on the most representative TMY.

The TMY to be used in future designs of solar thermal systems for Chillan was selected by evaluating the TMYs generated with SF values for a thermal hot water system and comparing results to SF values calculated from the 15 years of measured data. In this case, the TMY selected was the one closest to the mean and median of the results obtained in each of the seven simulations (one for each configuration of the solar thermal system) made for each year.

The method that best represents Chillan was the ASHRAE method using DT. This method was the one closest to the mean and median of all data in the seven simulations in TRNSYS. Its proximity position moved from 3 to 6 among the 25 years evaluated, which is considered as a reliable value. The second closest TMY data set occupied positions from 7 to 9 and corresponded to N-DT and Y-DT methods, since both generated the same TMY. 
The selected TMY provides a typical year. Nevertheless, to evaluate a design in the best or worst radiation conditions, a margin of error should be allowed in the upper and lower limits, which may be \pm 2 for the winter months and \pm 1 for the summer months. Higher or lower radiation levels particularly depend on the winter months during either El Niño or La Niña years (dry or wet years).

The construction of a TMY by ASHRAE with DT data using a greater number of years can provide a more representative TMY for Chillan, and also describe weather patterns more accurately. This valuable information can be used for future designs in the area. Based on the results obtained, it can also be concluded that the ASHRAE method should be the one used for TMYs of nearby locations in the future.

\section{ACKNOWLEDGMENTS}

The work was financially sponsored by the DIUC project named 'Conservation of fruit through solar refrigeration', University de Concepción and INNOVA -Biobío.

\section{REFERENCES}

[1] Apple L.S. Chan, T.T. Chow, Square K.F. Fong, John Z. Lin. Generation of a typical meteorological year for Hong Kong. Energy Conversion and Management 47 (2006) 87-96.

[2] Central Energy. Central information and discussion of energy in Chile. editores@centralenergia.cl. July 2014. (http://www.centralenergia.cl/)

[3] Francisco J. Collado, Jesus Gualla. A review of optimized design layouts for solar power tower plants with campo code. Renewable and Sustainable Energy Reviews 20 (2013) 142-154.

[4] Isabel Llorente García, Jose' Luis Álvarez, Daniel Blanco. Performance model for parabolic trough solar thermal power plants with thermal storage: Comparison to operating plant data. Solar Energy 85 (2011) 2443-2460.

[5] Liu Yang, Joseph C. Lam, Jiaping Liu, C.L. Tsang. Building energy simulation using multi-years and typical meteorological years in different climates. Energy Conversion and Management 49 (2008) 113124.

[6] Abdulsalam Ebrahimpour, Mehdi Maerefat. A method for generation of typical meteorological year. Energy Conversion and Management 51 (2010) 410-417.

[7] Irving Hall, Richard Prairie, Herbet Anderson, Eldon Boes. Generation of typical meteorological years for 26 SOLMET stations. Sandia Laboratories energy report, 1978.

[8] Marion W, Urban K. User manual for TMY2. Colorado: National Renewable Energy Laboratory (NREL); 1995.

[9] S. Wilcox and W. Marion. Users Manual for TMY3 Data Sets. NREL National Renewable Energy Laboratory. Technical Report NREL/TP-581-43156 Revised May 2008.

[10] ASHRAE. ASHRAE Handbook; 1989 Fundamentals.

[11] Yingni Jiang. Generation of typical meteorological year for different climates of China. Energy, 35 (2010) 1946-1953.

[12] Liu Yang, Kevin K.W. Wan, Danny H.W. Li, Joseph C. Lam. A new method to develop typical weather years in different climates for building energy use studies. Energy 36 (2011) 6121-6129.

[13] Teresita Larrain, Rodrigo Escobar, Julio Vergara. Performance model to assist solar thermal power plant siting in northern Chile based on backup fuel consumption. Renewable Energy 35 (2010) 1632-1643.

[14] Alberto Ortega, Rodrigo Escobar, Sergio Colle, Samuel Luna de Abreuc. The state of solar energy resource assessment in Chile. Renewable Energy 35 (2010) 2514 e2524.

[15] Kamal Skeiker. Comparison of methodologies for TMY generation using 10 years data for Damascus, Syria. Energy Conversion and Management 48 (2007) 2090-2102.

[16] Soteris A. Kalogirou. Generation of typical meteorological year (TMY-2) for Nicosia, Cyprus. Renewable Energy. Volume 28, Issue 15, December 2003, Pages 2317-2334.

[17] La Guía Metas. Temperatura de Punto de Rocío. Metas \& Metrólogos Asociados, November 2011.

[18] Duffie JA, Beckman WA. Solar energy of thermal processes. New York: John Wiley; 1980.

[19] Solar Energy Laboratory, Univ. of Wisconsin-Madison. Manual TRNSYS 17, a TRansientSYstem Simulation program. TRANSSOLAR, CSTB \& TESS. 